Check for updates

Cite this: RSC Adv., 2017, 7, 33441

Received 25th May 2017

Accepted 16th June 2017

DOI: $10.1039 / c 7 r a 05887 j$

rsc.li/rsc-advances

\section{Highly selective production of heavy hydrocarbons over cobalt-graphene-silica nanocomposite catalysts $\uparrow$}

\begin{abstract}
Jian Huang, (DD Weixin Qian, Hongfang Ma, Haitao Zhang and Weiyong Ying*
Herein, cobalt-graphene-silica nanocomposites were prepared by a sol-gel method to produce heavy hydrocarbons for Fischer-Tropsch synthesis. The catalysts were characterized by $\mathrm{N}_{2}$ physisorption, XRD, TEM, TPR, TPD, XPS, and DRIFTS techniques. The activity of catalysts and the selectivity of products were examined in a tubular fixed-bed reactor. It can be concluded that the introduction of graphene into cobalt-silica nanocomposites significantly enhanced the amount and stability of adsorbed $\mathrm{CO}$ at low temperatures, resulting in higher concentrations of $\mathrm{CO}$ species on the catalyst surface. Moreover, graphene can weaken the cobalt-silica interaction, leading to higher degree of reduction of cobalt oxides and higher adsorption amounts of $\mathrm{H}_{2}$. In addition, the introduction of graphene led to the formation of cobalt with smaller particle sizes, which contributed to great enhancement of $\mathrm{CO}$ conversion. The selectivity to methane distinctly decreased to $4.2 \%$ from $8.1 \%$, whereas the selectivity to $\mathrm{C}_{5}{ }^{+}$products increased from $84.5 \%$ to $92.4 \%$. The $\alpha$ value increased from 0.89 for the Co-Si catalyst to 0.94 for the Co-0.1GSi catalyst. In addition, with the increase in the graphene content, the fraction of heavy hydrocarbons $\left(\mathrm{C}_{19-29}\right)$ for catalysts evidently increased to $36.0 \%$ from $28.3 \%$, but the fraction of naphtha $\left(C_{5-12}\right)$ clearly reduced to $17.7 \%$ from $27.7 \%$.
\end{abstract}

\section{Introduction}

Due to the anticipated depletion of fossil energy sources, efforts have been made to replace conventional fuels with renewable energy sources via Fischer-Tropsch synthesis (FTS). ${ }^{1}$ The FTS process involves the formation of linear hydrocarbon molecules from the synthesis gas derived from coal, natural gas, or biomass through gasification, water steam reforming, or partial thermal oxidation. ${ }^{2,3}$ FTS has been considered as a promising technology to produce ultrapure transportation fuels and high value-added chemicals due to the global shortage of transportation fuels and environmental pollution..$^{4-6}$ The synthesis gas is converted in the presence of iron, cobalt, or ruthenium catalysts with highest activity, and the product distribution is extremely reliant on the FTS operating conditions and the type of the catalyst used..$^{7-9}$ Therefore, the selective synthesis of specific products is still one of the most critical issues in the FTS industry. ${ }^{\mathbf{1 0}}$

Moreover, cobalt is a favored active component of the FTS catalysts for the production of heavy hydrocarbons due to its high activity for carbon monoxide hydrogenation, low selectivity

Engineering Research Center of Large Scale Reactor Engineering and Technology, Ministry of Education, State Key Laboratory of Chemical Engineering, East China University of Science and Technology, Shanghai 200237, China. E-mail: wying@ ecust.edu.cn; Fax: +862164252192; Tel: +862164252151

$\dagger$ Electronic supplementary information (ESI) available. See DOI: 10.1039/c7ra05887j towards carbon dioxide, and long life span as compared to iron.112 With high cobalt loadings and low metal-support interactions, agglomeration and large cluster formation of cobalt nanoparticles during the process of calcination are difficult to avoid. ${ }^{13}$ Therefore, controlling the size of metal nanoparticles on supports is an effective means to obtain highly thermostable catalysts. $^{\mathbf{1 4}}$

Catalytic properties and the microstructure of the FTS catalysts are highly correlated with the carriers such as silica, alumina, titania, and zeolites. ${ }^{\mathbf{1 4 - 1 7}}$ The influence of the supports and their porosity has been extensively investigated on conventional oxide carriers. ${ }^{18-20}$ Supports with wide pores could accelerate the formation of larger $\mathrm{Co}_{3} \mathrm{O}_{4}$ particles, but large cobalt particle sizes would lead to less Co dispersion. ${ }^{21}$ It is believed that traditional oxides supports are highly stable and comparatively inert. However, their metal-support interaction is still relatively strong, and they have a major impact on the textural and chemical properties of the deposited surface layer as compared to carbon material supports such as carbon nanotubes ${ }^{22}$ or graphene. ${ }^{23}$ Therefore, the metal-support interactions can be adjusted via improvement of the supports to some extent. ${ }^{24}$

Recently, graphene has exhibited unique characteristics and outstanding adjustability in supporting various metallicsupported catalysts. ${ }^{25,26}$ It can be regarded as a significantly potential support material for metal particle catalysts because of its unique electronic, thermal, textural, and chemical properties. $^{27}$ Furthermore, with a large surface area and high 
adsorption capacity, graphene can serve as a valuable substrate to interact with various species. ${ }^{\mathbf{2 6 , 2 8}}$ Cobalt-graphene-supported catalysts were prepared by an impregnation method; these catalysts showed higher cobalt dispersion and decreased the average size of the clusters of cobalt oxides, exhibiting higher electronic interaction. ${ }^{29}$ Moreover, it was found that graphene, as a carrier, could lower the reduction temperature of metal oxides. ${ }^{30,31}$ However, it is difficult to utilize graphene-supported catalysts in industry due to the fact that graphene has low mechanical strength and is difficult to shape. Therefore, these were anticipated to combine the unique electronic and structural characteristics of graphene with high stability and comparative inertness of conventional carriers.

In this study, we focused on the effects of graphene on cobalt-graphene-silica nanocomposites, which were prepared by the sol-gel method and tested under FTS conditions in a fixed tube reactor to study the effects on the selectivity and distribution of products. Characterization methods such as $\mathrm{N}_{2}$ adsorption, X-ray diffraction (XRD), transmission electron microscopy (TEM), temperature-programmed reduction (TPR), X-ray photoelectron spectroscopy (XPS), temperatureprogrammed desorption (TPD), and in situ diffuse reflectance infrared Fourier transform spectroscopy (DRIFTS) were applied to characterize the catalysts. The effects of graphene content on the texture, reduction properties, chemisorption, and FTS performance of the catalysts was investigated.

\section{Experimental}

\subsection{Catalyst preparation}

Co-graphene-silica nanocomposites were prepared in situ by a sol-gel method with commercial silica sol (34 wt $\% \mathrm{SiO}_{2}, \mathrm{pH}=$ 3.0), graphene (99.5 wt\%, Chengdu Organic Chemicals Co., LTD., Chinese Academy of Sciences), and cobalt(II) nitrate hexahydrate (>99 wt\% Sinopharm Chemical Reagent Co., Ltd) as precursor solutions. In a typical preparation process, $12.59 \mathrm{~g}$ of cobalt nitrate hexahydrate was completely dissolved in $15 \mathrm{~mL}$ of deionized water and mixed with $30 \mathrm{~g}$ silica sol and $x(0,10.2,51$, and 102) $\mathrm{mg}$ of graphene under vigorous stirring at $25^{\circ} \mathrm{C}$ for $2 \mathrm{~h}$. The mixtures were placed in a drying oven and heated to $110{ }^{\circ} \mathrm{C}$ in an air atmosphere at a heating rate of $10{ }^{\circ} \mathrm{C} \mathrm{min}^{-1}$ for $24 \mathrm{~h}$ to form a viscous gel. Subsequently, the obtained dried viscous gel was calcined at $400{ }^{\circ} \mathrm{C}$ for $6 \mathrm{~h}$ at the given heating rate of $2{ }^{\circ} \mathrm{C}$ $\min ^{-1}$ under a $\mathrm{N}_{2}$ stream. The prepared samples were denoted as
Co- $x$ GSi $(x=0.1,0.5$, and 1.0), where $x$ wt $\%$ represents the content of graphene and $\mathrm{G}$ represents graphene. The sample without graphene was denoted as Co-Si. The cobalt loadings of the catalysts were measured via ICP-AES technology (Agilent 725ES, USA), detailed in Table 1. To compare the differences in the texture properties of the catalysts and supports, silica and graphene-silica nanocomposites (0.5 wt $\%$ graphene) were prepared by a similar method and signified as $\mathrm{SiO}_{2}$ and $0.5 \mathrm{GSi}$.

\subsection{Catalyst characterization}

$\mathrm{N}_{2}$ physisorption was measured using a Micrometrics ASAP 2020 physisorption device at liquid $\mathrm{N}_{2}$ temperature. Specific surface areas were measured by the Brunauer Emmett Teller (BET) method. Total pore volume and pore sizes were measured by the Barrett-Joyner-Halenda (BJH) procedure.

XRD profiles of the catalysts were obtained using a Rigaku D/ Max2550VB/PC with $\mathrm{Cu} \mathrm{K \alpha}$ radiation $(\lambda=0.154 \mathrm{~nm})$ at $40 \mathrm{kV}$ and $100 \mathrm{~mA}$. The average $\mathrm{Co}_{3} \mathrm{O}_{4}$ crystallite sizes were estimated by the Scherrer equation using the $\mathrm{Co}_{3} \mathrm{O}_{4}$ peak at $36.9^{\circ}$ and a $K$ factor of 0.89 . These particle sizes could be switched to the corresponding particle sizes of $\mathrm{Co}^{0}$ according to $d_{\mathrm{Co}}=$ $0.75 d_{\mathrm{Co}_{3} \mathrm{O}_{4}}{ }^{32}$

TEM images and elemental mapping of the catalysts were obtained using a JEOL JEM 2100FX microscope equipped with an energy dispersive X-ray detector (EDX, Oxford-INCA) at 200 $\mathrm{kV}$. The samples were dispersed in absolute ethanol, dropped on a copper grid, and dried under infra-red lamp for $15 \mathrm{~min}$. Carbon species of the samples were determined by an energy dispersive X-ray spectroscope (EDS, Falcon) equipped with a CDU X-ray detector. The samples for EDS measurements were coated on a copper stage by a conducting resin.

$\mathrm{H}_{2}$-TPR tests of the catalysts were performed using a Micrometrics AutoChem II 2920 equipment. Before the tests, about $50 \mathrm{mg}$ of the catalyst sample was swept in an argon flow at $350{ }^{\circ} \mathrm{C}$ for $2.0 \mathrm{~h}$ to remove the residual water in the catalysts. After being cooled down to $50{ }^{\circ} \mathrm{C}$, each sample was heated up to $800{ }^{\circ} \mathrm{C}$ at a heating rate of $10{ }^{\circ} \mathrm{C} \mathrm{min}^{-1}$ in a $10 \% \mathrm{H}_{2} / 90 \% \mathrm{Ar}(\mathrm{v} / \mathrm{v})$

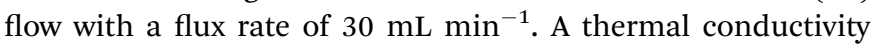
detector (TCD) was applied to measure $\mathrm{H}_{2}$ consumption.

XPS spectra of the samples were obtained by a VG ESCALAB 250Xi electron spectrometer with an Al-K $\alpha$ X-ray source operating at $10 \mathrm{~mA}$ and $12 \mathrm{kV}$. The binding energies of the cobalt species were referenced to $\mathrm{C} 1 \mathrm{~s}$ at $284.8 \mathrm{eV}$. The curves of the

Table 1 Co loading, surface area, pore volume, average pore diameter, and Co particle size for samples

\begin{tabular}{|c|c|c|c|c|c|c|c|}
\hline Sample & Co loading ${ }^{a}(\%)$ & $S_{\mathrm{BET}}\left(\mathrm{m}^{2} \mathrm{~g}^{-1}\right)$ & $V_{\mathrm{p}}{ }^{b}\left(\mathrm{~cm}^{3} \mathrm{~g}^{-1}\right)$ & $D_{\mathrm{p}}^{c}(\mathrm{~nm})$ & $d_{\mathrm{Co}_{3} \mathrm{O}_{4}}{ }^{d}(\mathrm{~nm})$ & $d_{\mathrm{Co}}^{e}(\mathrm{~nm})$ & $d_{\mathrm{Co}}^{f}(\mathrm{~nm})$ \\
\hline $\mathrm{Co}-\mathrm{Si}$ & 21.8 & 130 & 0.35 & 10.2 & 22.7 & 17.0 & 9.7 \\
\hline Co-0.1GSi & 21.6 & 132 & 0.38 & 11.4 & 21.4 & 16.1 & 8.6 \\
\hline Co-0.5GSi & 21.4 & 135 & 0.39 & 11.3 & 18.0 & 13.5 & 8.2 \\
\hline Co-1.0GSi & 21.3 & 153 & 0.44 & 11.0 & 17.0 & 12.8 & 7.9 \\
\hline $0.5 \mathrm{GSi}$ & - & 185 & 0.29 & 6.2 & - & - & - \\
\hline $\mathrm{SiO}_{2}$ & - & 164 & 0.29 & 6.7 & - & - & - \\
\hline
\end{tabular}

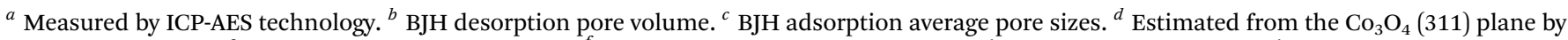
Scherrer's equation. ${ }^{e}$ Calculated by $d_{\mathrm{Co}}=0.75 d_{\mathrm{Co}_{3} \mathrm{O}_{4} \cdot}{ }^{f}$ Estimated by $\mathrm{H}_{2}$-TPD and $d=96 / D(D \%$ is dispersion of cobalt). 
samples were fitted to the Lorentzian/Gaussian lines after subtracting a Shirley-shaped background.

Both $\mathrm{H}_{2}$-TPD and CO-TPD-GC-MSD measurements were performed using a Micrometrics AutoChem II 2920 device, and about $200 \mathrm{mg}$ of the catalyst was reduced in a $\mathrm{H}_{2}$ flow $(50 \mathrm{~mL}$ $\min ^{-1}$ ) at $400{ }^{\circ} \mathrm{C}$ for $4 \mathrm{~h}$ and purged under a He flow for $30 \mathrm{~min}$. After cooling to $50{ }^{\circ} \mathrm{C}, \mathrm{H}_{2}$ or $\mathrm{CO}$ was introduced until saturation, and then, the catalyst was swept by a He flow until the baseline was flat. Subsequently, the sample was heated under a He flow at a rate of $10{ }^{\circ} \mathrm{C}$, and a TCD detector was used to detect the desorbed $\mathrm{CO}$ or $\mathrm{H}_{2}$. The dispersion of cobalt can be estimated by the desorption amount of $\mathrm{H}_{2}$ on the $\mathrm{Co}^{0}$ surface. The tail gas of the CO-TPD measurements was detected via GC-MSD (Agilent 7890A-5975C).

In situ DRIFTS measurements were performed using a Nicolet 6700 spectrometer equipped with an MCT detector (Thermo, USA). The sample was reduced in $\mathrm{H}_{2}$ for $12 \mathrm{~h}$ at $400{ }^{\circ} \mathrm{C}$ and then swept by pure $\mathrm{N}_{2}$ for $30 \mathrm{~min}$. The backgrounds were obtained when the vacuum degree of the in situ cell was below $10^{-4} \mathrm{~Pa}$. Then, $5 \% \mathrm{CO} / \mathrm{He}$ was introduced at $205{ }^{\circ} \mathrm{C}$ for $30 \mathrm{~min}$. Subsequently, $10 \% \mathrm{H}_{2} / \mathrm{Ar}$ was introduced at $30 \mathrm{~mL} \mathrm{~min}^{-1}$, and the outlet of the in situ cell was closed. The spectra of the catalysts were obtained using a resolution of $4 \mathrm{~cm}^{-1}$ and an accumulation of 64 scans at $0,5,15,30$, and $60 \mathrm{~min}$.

\subsection{Catalyst evaluation}

The performance of the cobalt catalysts was tested in a fixed-bed reactor (ID $10 \mathrm{~mm}$ ). The catalyst loading was $1.00 \mathrm{~g}$, and its particle size was $48-75 \mu \mathrm{m}$. In addition, the catalyst was mixed with $2.6 \mathrm{~g}$ of quartz grains with the same particle size. All the catalysts were reduced at atmospheric pressure, $400{ }^{\circ} \mathrm{C}$, and a space velocity of $3000 \mathrm{~cm}^{3} \mathrm{STP}$ per $\mathrm{g}$ per $\mathrm{h}$ under a flow of pure $\mathrm{H}_{2}$ for $24 \mathrm{~h}$. After cooling to $150{ }^{\circ} \mathrm{C}$, the syngas was introduced, and the experimental reaction conditions were maintained at a temperature of $205{ }^{\circ} \mathrm{C}$, a pressure of $2.0 \mathrm{MPa}$, and space velocity of $2800 \mathrm{~cm}^{3} \mathrm{STP}$ per $\mathrm{g}$ per $\mathrm{h}$ in the reaction system. The reaction products were introduced into a hot trap $\left(180^{\circ} \mathrm{C}\right)$ and a cold trap $\left(0{ }^{\circ} \mathrm{C}\right)$ to separate water, oil, and wax.

Moreover, two Agilent 7890A GCs equipped with different columns and detectors were applied to analyze the FTS products; then, two TCDs were applied to detect $\mathrm{CO}, \mathrm{H}_{2}, \mathrm{~N}_{2}$, and $\mathrm{CO}_{2}$, which were separated using $5 \mathrm{~A}$ molecular sieves and Propack Q packed columns. A flame ionization detector (FID) was applied to detect $\mathrm{C}_{1-6}$ hydrocarbons separated using a HP$\mathrm{AL} / \mathrm{S}$ capillary column. The components of the gas products were quantified by an external standard method with the standard gas containing $\mathrm{CO}, \mathrm{H}_{2}, \mathrm{~N}_{2}, \mathrm{CO}_{2}$, and $\mathrm{C}_{1-6}$ hydrocarbons. The oil product was analyzed using a HP-5 capillary column, and the wax product was dissolved in $\mathrm{CS}_{2}$ and separated using a DB-5ht capillary column, and both oil and wax were detected via FID. The quantification of wax and oil was calculated by an area percentage.

All the reported data about catalyst performance were obtained after $50 \mathrm{~h}$ on stream to ensure steady-state behavior and representative product samples. The conversion of $\mathrm{CO}$ denoted as $X_{\mathrm{CO}}$ could be calculated by

$$
X_{\mathrm{CO}}(\%)=\frac{N_{\mathrm{CO}, \text { in }}-N_{\mathrm{CO}, \text { out }}}{N_{\mathrm{CO}, \text { in }}} \times 100
$$

The selectivity of $\mathrm{C}_{n}$ hydrocarbons denoted as $S_{\mathrm{C}_{n}}$ could be calculated by

$$
S_{\mathrm{C}_{n}}(\%)=\frac{n \times N_{\mathrm{C}_{n} \text { out }}}{N_{\mathrm{CO}, \text { in }}-N_{\mathrm{CO}, \text { out }}} \times 100
$$

where $N$ represents the molar flow rate $\left(\mathrm{mol} \mathrm{h}^{-1}\right)$ and $n$ represents the carbon number of the hydrocarbons.

\section{Results and discussion}

\subsection{Catalyst characterization}

3.1.1. $\mathbf{N}_{2}$ physisorption. The textures of the Co-graphenesilica nanocomposites were measured by $\mathrm{N}_{2}$ physisorption. The specific surface area $\left(S_{\mathrm{BET}}\right)$, total pore volume $\left(V_{\mathrm{p}}\right)$, and average pore size $\left(D_{\mathrm{p}}\right)$ of the samples are summarized in Table 1 . The Co-Si catalyst had a surface area of $130 \mathrm{~m}^{2} \mathrm{~g}^{-1}$, pore volume of $0.35 \mathrm{~cm}^{3} \mathrm{~g}^{-1}$, and average pore size of $10.2 \mathrm{~nm}$. With the increasing loading of graphene, the surface area of the graphene-modified cobalt catalysts increased from $132 \mathrm{~m}^{2} \mathrm{~g}^{-1}$ to $153 \mathrm{~m}^{2} \mathrm{~g}^{-1}$, whereas both its pore volume and average pore size slightly enlarged. This was probably due to the existence of graphene in the process of sample preparation, which can inhibit the formation of large particle species. However, the $S_{\mathrm{BET}}$ of $\mathrm{SiO}_{2}$ was clearly larger than that of Co- $x \mathrm{GSi}$, but the $V_{\mathrm{p}}$ and $D_{\mathrm{p}}$ of $\mathrm{SiO}_{2}$ were evidently smaller than those of Co- $x \mathrm{GSi}$ due to the decomposition of cobalt nitrate over the dried gel, resulting in a significant increase in the sizes of the pore.

The pore size distributions of $\mathrm{Co}-x \mathrm{GSi}$ and $\mathrm{SiO}_{2}$ are shown in Fig. S1 (details in the ESI $\dagger$ ). It is clear that a pore size distribution of around 10-20 nm was observed for each catalyst sample, whereas a pore size distribution of around 5-8 nm was observed for $\mathrm{SiO}_{2}$.

The difference between both types of samples was that the precursors of Co- $x$ GSi contained nitrate species, which could be considered as a pore-forming agent due to the fact that cobalt nitrate could be thermally decomposed as nitric oxides during heating, leading to larger pore sizes. In consideration of the introduction of graphene, the pore size distributions of catalysts slightly narrowed, and the average pore size slightly enlarged.

3.1.2. X-ray diffraction. The XRD patterns of the fresh catalysts strongly indicated the presence of $\mathrm{Co}_{3} \mathrm{O}_{4}$, as presented in Fig. 1(A). The peaks observed at $2 \theta$ of $21.27^{\circ}, 36.84^{\circ}, 44.8^{\circ}$, $55.65^{\circ}, 59.35^{\circ}$, and $65.22^{\circ}$ were in accordance with the different crystal planes of $\mathrm{Co}_{3} \mathrm{O}_{4} \cdot{ }^{20}$ Moreover, in the case of silicasupported catalysts, a broad peak at $2 \theta$ of $22^{\circ}$ (from $15^{\circ}$ to $38^{\circ}$ ) indicated the presence of amorphous silica. ${ }^{33}$ No carbon species were detected in the X-ray diffraction patterns probably because of the low concentration of carbon. Thus, all these catalysts had the same phases: amorphous silica and cubic $\mathrm{Co}_{3} \mathrm{O}_{4}$.

The only difference between the XRD results of the calcined catalysts was the half-peak width and intensity of the $\mathrm{Co}_{3} \mathrm{O}_{4}$ peaks. The $\mathrm{Co}_{3} \mathrm{O}_{4}$ crystallite sizes of the samples diminished with the addition of graphene, as shown in Table 1 . The results 

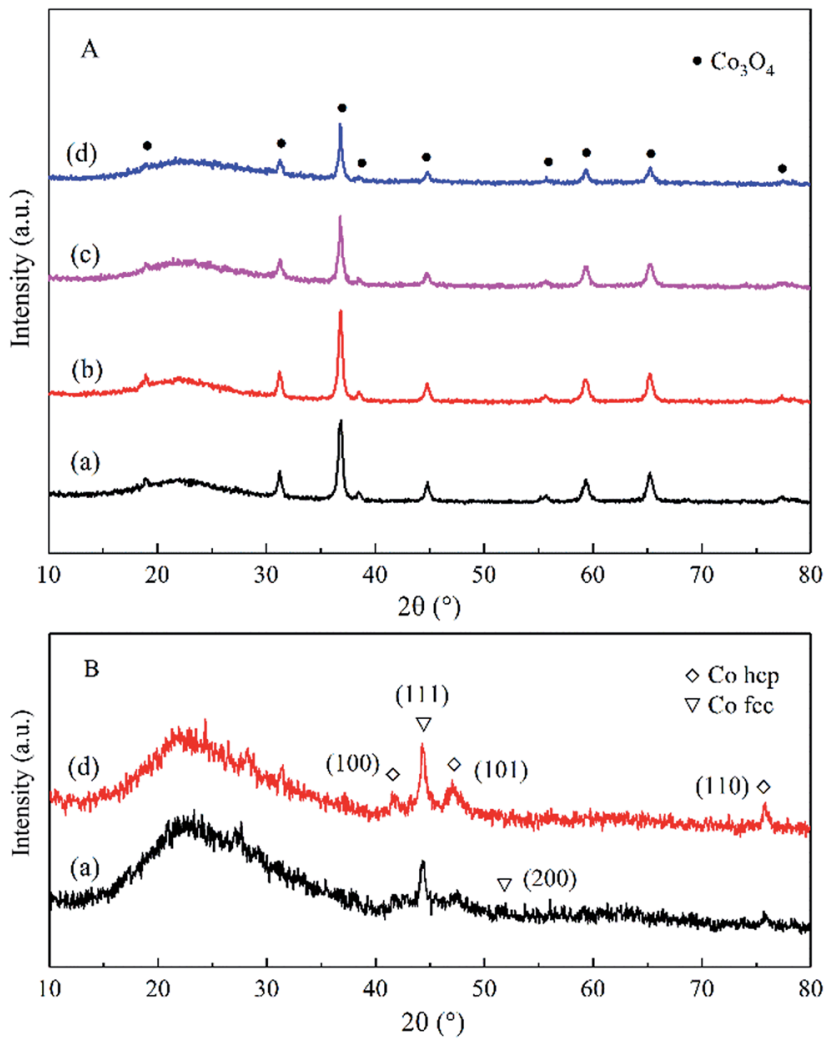

Fig. 1 XRD patterns of the calcined catalysts (A) and reduced catalysts (B): (a) Co-Si, (b) Co-0.1GSi, (c) Co-0.5GSi, and (d) Co-1.0GSi.

showed that introduction of graphene in cobalt-silica nanocomposites resulted in significant decrease in the sizes of the $\mathrm{Co}_{3} \mathrm{O}_{4}$ nanoparticles as compared to the sample without carbon species. ${ }^{9}$ According to Fig. 1(B), the cobalt species of reduced catalysts were mainly hexagonal close packed (hcp) and facecentered cubic (fcc) crystal phases. ${ }^{34}$

3.1.3. Transmission electron microscopy. The TEM images of the samples are shown in Fig. 2. The dark spots were the particles of the catalyst, and more agglomeration occurred in the process of TEM sample preparation.

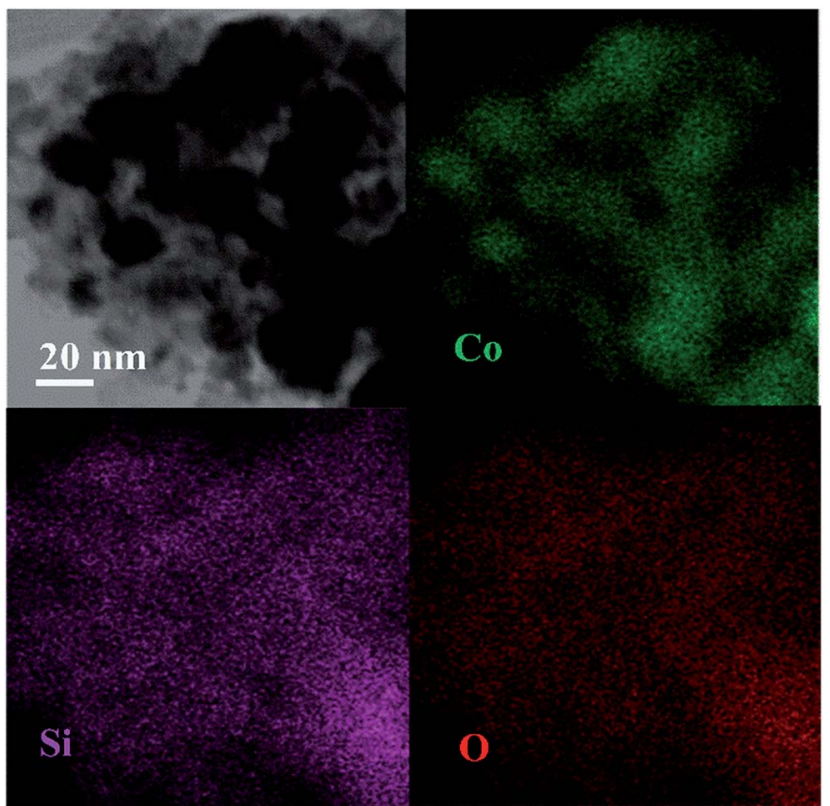

Fig. 3 EDS-mapping of the reduced Co-1.0GSi catalyst: elemental mapping of cobalt (Co), silicon (Si), and oxygen (O)

The grains sizes of the catalysts were approximately $20 \mathrm{~nm}$, and the dispersion of cobalt oxides of both catalysts was relatively high, as observed in Fig. 2(a)-(d). Thus, the sizes of the catalysts grains were in the nanoscale, and the synthesized samples were nanocomposites. The TEM image of the reduced Co-1.0GSi catalyst is shown in Fig. 2(e). From this TEM image, it was observed that the crystal texture of the metallic cobalt phase was mainly hep cobalt (101) and less fcc cobalt (200) was observed. According to the XRD results, it was demonstrated that the hcp phase of the reduced cobalt catalysts was much more easily exposed than the fcc cobalt (200) phase on the catalyst surface. ${ }^{34}$

The influence of carbon species on resisting the formation of a $\mathrm{Co}_{2} \mathrm{SiO}_{4}$ spinel may be due to cobalt that was scattered by graphene species, which obstructed the immediate strong

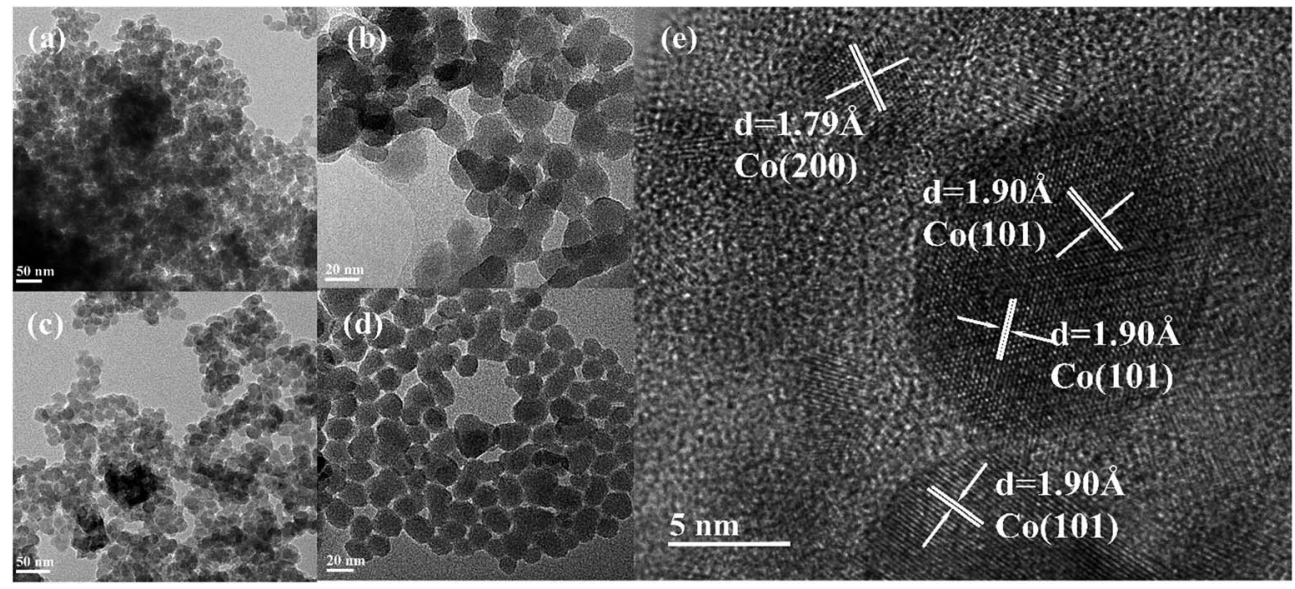

Fig. 2 TEM images of the calcined Co-Si ( $a$ and b) and Co-1.0GSi (c and d). TEM images of the reduced Co-1.0GSi (e). 
interaction between cobalt and silica particles. This hypothesis was studied in more detail via the EDS-mapping technology. Elemental mapping of the calcined Co-1.0GSi sample is presented in Fig. 3. As can be clearly deduced from the mapping, the surface of the sample has more exposed cobalt particles. Carbon species of the Co-1.0GSi sample was determined by EDS, as shown in Fig. S2. $\dagger$ The carbon content was $1.24 \mathrm{wt} \%$, and the cobalt content was almost in agreement with the results of ICP-AES.

3.1.4. Temperature-programmed reduction. The reducibility of the oxidized samples and the metal-support interaction were studied by $\mathrm{H}_{2}$-TPR, as presented in Fig. 4 . The curves showed two apparent reduction peaks centered at approximately $280{ }^{\circ} \mathrm{C}$ and $390{ }^{\circ} \mathrm{C}$. The reduction patterns of the $\mathrm{Co}_{3} \mathrm{O}_{4}$ particles have generally been known to originate via two-step reductions as follows: ${ }^{4}$

$$
\begin{aligned}
& \mathrm{Co}_{3} \mathrm{O}_{4}+\mathrm{H}_{2} \rightarrow 3 \mathrm{CoO}+\mathrm{H}_{2} \mathrm{O} \\
& \mathrm{CoO}+3 \mathrm{H}_{2} \rightarrow 3 \mathrm{Co}^{0}+3 \mathrm{H}_{2} \mathrm{O}
\end{aligned}
$$

The first reduction peaks below $350{ }^{\circ} \mathrm{C}$ can be ascribed to the reduction of $\mathrm{Co}_{3} \mathrm{O}_{4}$ to $\mathrm{CoO}$, and the second peak is attributed to the reduction of $\mathrm{CoO}$ to metallic cobalt. For $\mathrm{Co}_{3} \mathrm{O}_{4}$ species, the hydrogen consumption ratio between the reduction of $\mathrm{Co}^{3+}$ to $\mathrm{Co}^{2+}$ with that of $\mathrm{Co}^{2+}$ to $\mathrm{Co}^{0}$ is one to three, according to eqn (3) and (4). Thus, the reduction curves of the catalysts can be decomposed as three peaks (noted as $\alpha, \beta$, and $\gamma$ ), with the hypothesis that a proportion of one part by the first peak areas at low temperatures to three parts by another peak area can be used, as presented in Table S1 (details in the ESI $\dagger$ ). Based on this assumption, the results of the TPR profiles showed that the reduction temperature of $\mathrm{Co}-x \mathrm{GSi}$ catalysts decreased from $335{ }^{\circ} \mathrm{C}$ to $326{ }^{\circ} \mathrm{C}\left(\alpha\right.$ : $\mathrm{Co}^{3+}$ to $\left.\mathrm{Co}^{2+}\right), 376{ }^{\circ} \mathrm{C}$ to $368{ }^{\circ} \mathrm{C}(\beta$ : partial $\mathrm{Co}^{2+}$ to $\left.\mathrm{Co}^{0}\right)$, and $410{ }^{\circ} \mathrm{C}$ to $390{ }^{\circ} \mathrm{C}\left(\gamma\right.$ : remaining $\mathrm{Co}^{2+}$ to $\left.\mathrm{Co}^{0}\right)$.

Moreover, the hydrogen consumption increased from $19 \%$ to $42 \%$ at the $\beta$ peak, but decreased from $56 \%$ to $33 \%$ at the $\gamma$

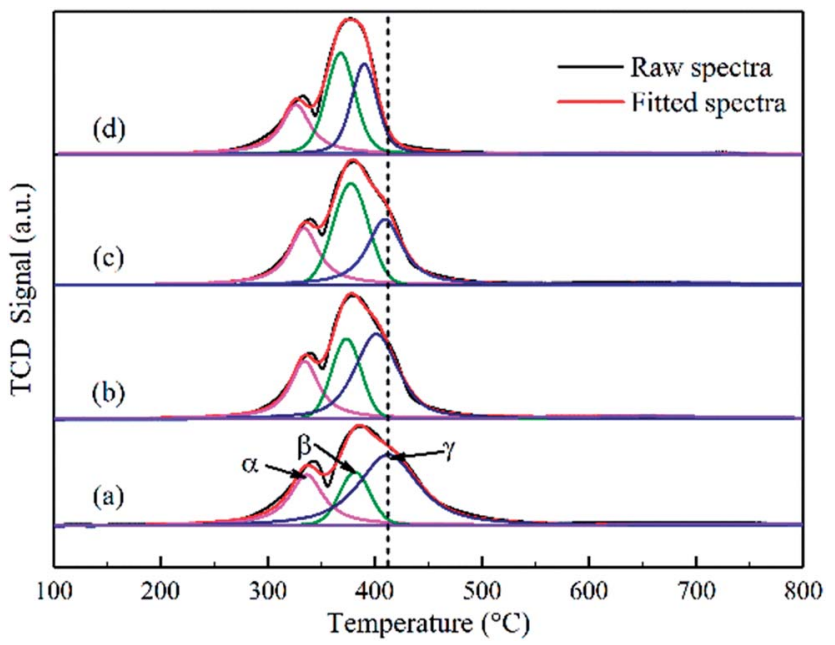

Fig. 4 Hydrogen temperature-programmed reduction of the calcined catalysts: (a) Co-Si, (b) Co-0.1GSi, (c) Co-0.5GSi, and (d) Co-1.0GSi.

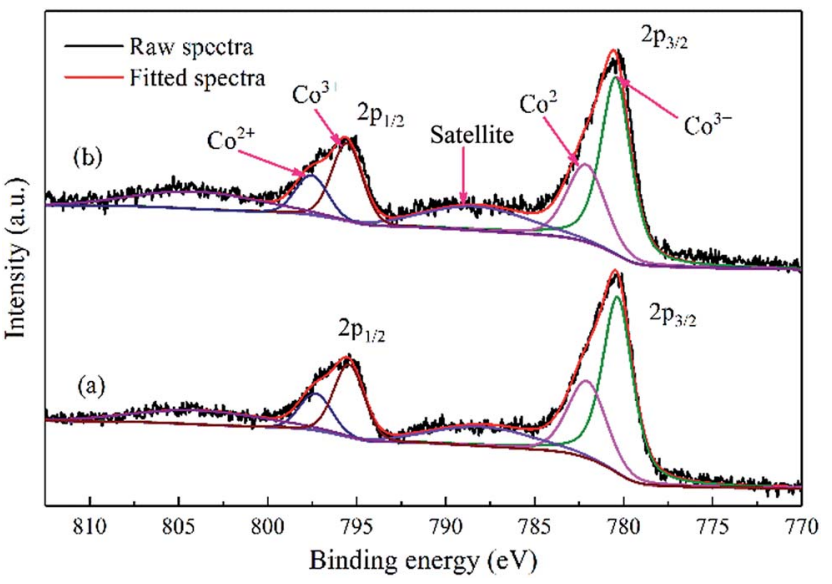

Fig. 5 XPS spectra of the calcined cobalt catalysts: (a) Co-Si and (b) Co-1.0GSi.

peak. From Table S1, $\uparrow$ it was observed that the degree of reduction increased from $86.9 \%$ to $97.2 \%$ with an increase in the graphene content. Accordingly, most cobalt oxide was converted into metallic cobalt during the reduction process, which could provide more metal cobalt clusters and more active sites. Therefore, it also indicates that the addition of graphene can decrease the interaction between cobalt oxide and the silica support and significantly facilitate the reduction of $\mathrm{Co}^{2+}$ to $\mathrm{Co}^{0}$. This could be due to the fact that graphene located at the interface between cobalt and silica decreased the formation probability of cobalt species, which was difficult to reduce..$^{35,36}$

3.1.5. X-ray photoelectron spectroscopy. XPS spectra of the calcined catalysts are presented in Fig. 5, and the binding energy of cobalt oxide species was referenced to the data obtained from the NIST database. ${ }^{37}$ XPS spectra of $\mathrm{a} \mathrm{Co}_{3} \mathrm{O}_{4}$ standard was applied to confirm the cobalt oxidation species. ${ }^{38}$ The most primary cobalt species is $\mathrm{Co}_{3} \mathrm{O}_{4}$ in unreduced catalysts, which is also identified by XRD shown in Fig. 1.

The binding energy of Co $2 \mathrm{p}_{3 / 2}$ for Co-1.0GSi was $779.9 \mathrm{eV}$, slightly larger than that of $\mathrm{Co}-\mathrm{Si}(779.8 \mathrm{eV})$, as presented in Table $\mathrm{S} 2, \dagger$ since the charge transfer became relatively facile in the presence of graphene. ${ }^{20}$ Therefore, the charge density of cobalt atoms on the catalyst surface decreased with the addition of graphene.

From Table S2 (details in the ESI $\dagger$ ), it is apparent that the atomic ratio of $\mathrm{Co} / \mathrm{Si}$ for the $\mathrm{Co}-1.0 \mathrm{GSi}$ sample is $8.3 \%$ larger than that $(6.7 \%)$ of the Co-Si sample. This may be due to the fact that the exposure probability of cobalt species on the catalyst surface from silica becomes much larger in the preparation process with the addition of graphene. Hence, the catalysts with graphene had higher reducibility and higher atomic ratio of $\mathrm{Co} / \mathrm{Si}$, which was consistent with the results of $\mathrm{H}_{2}$-TPR and EDS-mapping.

3.1.6. $\mathrm{H}_{2} / \mathrm{CO}$ temperature-programmed desorption. $\mathrm{H}_{2}$ uptake of desorption for the catalysts was measured by $\mathrm{H}_{2}$-TPD, as summarized in Table 2. With an increase in the amounts of graphene, $\mathrm{H}_{2}$ uptake of desorption was obviously increased. In other words, the concentration of hydrogen species was lower 
Table 2 The temperature and uptake of $\mathrm{CO}$ desorption, degree of reduction (DoR), and $\mathrm{H}_{2}$ desorption uptakes for reduced catalysts

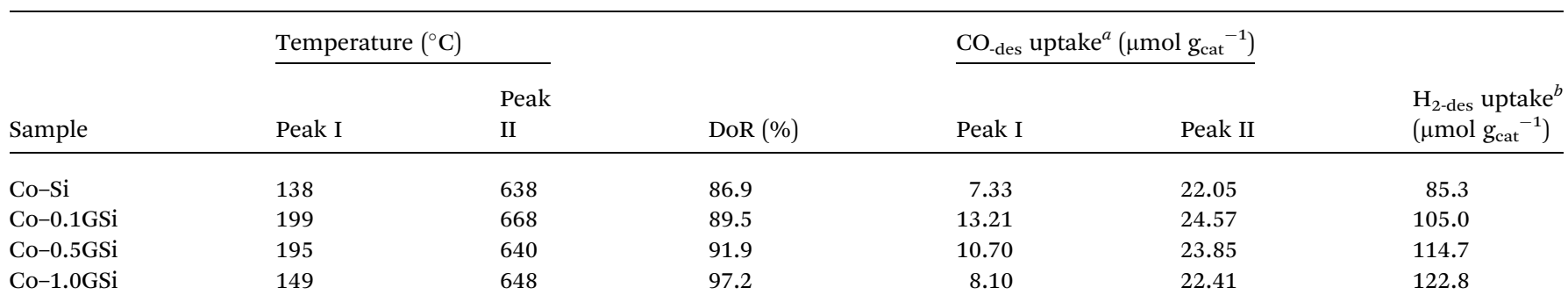

${ }^{a} \mathrm{CO}_{\text {-des }}$ uptake was corrected by measuring the component of tail gas. ${ }^{b} \mathrm{H}_{2 \text {-des }}$ uptake was measured by $\mathrm{H}_{2}$-TPD.

than that of the catalyst without graphene. To a certain extent, graphene could increase the adsorption capacity of $\mathrm{H}_{2}$ on the cobalt surface via its unique adsorption property. ${ }^{28}$

In addition, the $\mathrm{CO}$ adsorption on cobalt particles was measured by CO-TPD, and two CO desorption peaks were observed, as shown in Fig. 6. Based on the carbide mechanism, ${ }^{39}$ CO was directly dissociated after adsorption on the catalysts, resulting in $\mathrm{C}$ and $\mathrm{O}$ species. Consequently, with the addition of graphene, the low temperature peaks (peak I) of the catalysts were attributed to the molecular adsorption of $\mathrm{CO}$, dramatically increasing from 138 to $199{ }^{\circ} \mathrm{C}$, and the high temperature peaks (peak II) were ascribed to the dissociation of adsorbed CO. Moreover, the desorption amount of CO increased from $7.33 \mu \mathrm{mol} \mathrm{g}_{\text {cat }}{ }^{-1}$ to $13.21 \mu \mathrm{mol} \mathrm{g}$ cat $^{-1}$ with 0.1 wt $\%$ content of graphene. However, with the increasing graphene content from $0.1 \mathrm{wt} \%$ to $1.0 \mathrm{wt} \%$, the desorption amount of CO decreased from $13.21 \mu \mathrm{mol} \mathrm{g}_{\text {cat }}{ }^{-1}$ to $8.10 \mu \mathrm{mol} \mathrm{g}_{\text {cat }}{ }^{-1}$.

The results of CO-TPD show that via a proper content (0.1$0.5 \mathrm{wt} \%$ ) of graphene, the molecular adsorption intensity of $\mathrm{CO}$ was significantly increased, and the adsorbed CO molecules were more thermally stable, whereas the dissociative adsorption of CO was evidently increased. Moreover, higher reduction and smaller particle sizes of the Co- $x$ GSi catalysts can offer more

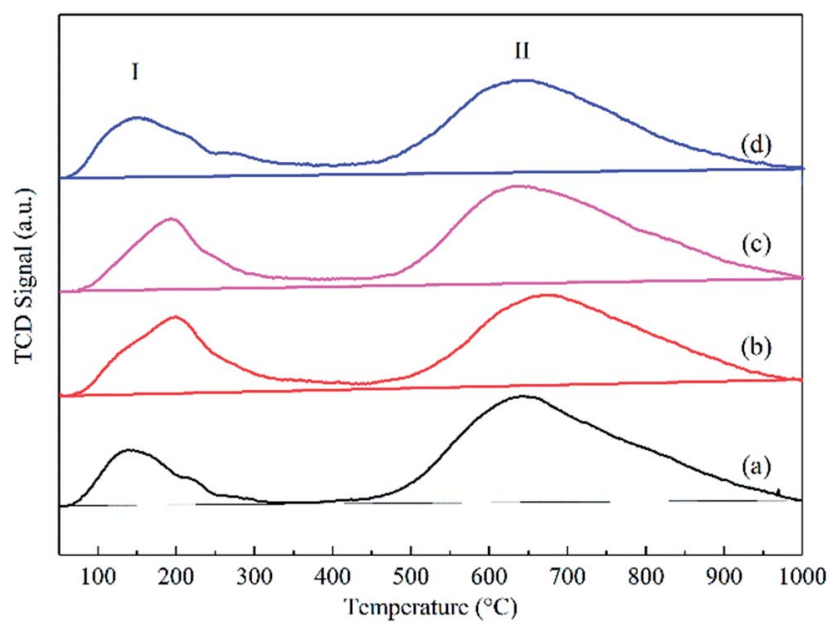

Fig. 6 Carbon monoxide temperature-programmed desorption curves of the reduced catalysts: (a) $\mathrm{Co}-\mathrm{Si}$, (b) $\mathrm{Co}-0.1 \mathrm{GSi}$, (c) $\mathrm{Co}-$ 0.5GSi, and (d) Co-1.0GSi. adsorption sites with more cobalt clusters, verified by the results of XRD and $\mathrm{H}_{2}$-TPR.

3.1.7. In situ diffuse reflectance infrared Fourier transform spectroscopy. The adsorption of $\mathrm{CO}$ as a probe molecule was applied to identify the influences of graphene on the adsorption properties of the catalyst by in situ DRIFTS, as shown in Fig. 7. After in situ reduction with $\mathrm{H}_{2}$ and evacuation, successive adsorption of $\mathrm{CO}$ was conducted for $30 \mathrm{~min}$, and the spectra were obtained at 0 minutes at $205^{\circ} \mathrm{C}$. Then, $\mathrm{H}_{2}$ was introduced, and the spectra were obtained at 5, 15, 30, and 60 minutes.

The band at 2176 and $2115 \mathrm{~cm}^{-1}$ was assigned to gaseous CO and was observed in all the spectra of the catalysts. ${ }^{\mathbf{4}}$ The band at $3015 \mathrm{~cm}^{-1}$ was attributed to $\mathrm{CH}_{4}$, and the band at 2850-3000 $\mathrm{cm}^{-1}$ was ascribed to the stretching of $\mathrm{CH}_{x}$ species. The most intense band at $2036 \mathrm{~cm}^{-1}$ observed in Fig. 7(a) was attributed to the adsorption of $\mathrm{CO}$ on $\mathrm{Co}^{\delta+}$ species, ${ }^{\mathbf{4 1}}$ where the electron density of cobalt became lower than that of the catalysts with graphene. However, the band at $2072 \mathrm{~cm}^{-1}$ observed in Fig. 7(c) was assigned to linear $\mathrm{CO}$ adsorption on top of metal Co particles. ${ }^{40}$ With an increasing content of graphene, this band was significantly shifted from 2036 to $2072 \mathrm{~cm}^{-1}$, indicating an increase of reduced cobalt species, ${ }^{\mathbf{4 2}}$ which was consistent with the results of $\mathrm{H}_{2}$-TPR. Moreover, the intensity of this band for the Co-0.1GSi catalyst was distinctly larger as compared to that for other catalysts. It was proven that the amount of $\mathrm{CO}$ molecular adsorption was significantly enhanced by the addition of 0.1 wt $\%$ graphene, confirmed by the results of CO-TPD shown in Table 2.

Moreover, with the hydrogenation reaction proceeding in situ in the cell, the gaseous CO was gradually consumed and the bands of $\mathrm{CO}$ adsorption clearly shifted towards lower wavenumber because of low coverage at low CO concentrations, as shown in Fig. 7. This also demonstrated that the presence of $\mathrm{H}_{2}$ accelerated the exclusion of adsorbed CO on weak sites. ${ }^{43}$

\subsection{Catalyst performance}

The performance of the graphene-modified catalysts is shown in Fig. 8, where the activity and selectivity were obtained after $50 \mathrm{~h}$. In addition, the FTS activity of the Co- $x$ GSi catalysts measured as the $\mathrm{CO}$ consumption rate per unit weight of the catalysts (weight-time yield, WTY) is presented in Table 3. The introduction of graphene in cobalt-silica nanocomposites obviously enhanced the FTS activity and selectivity to $\mathrm{C}_{5}{ }^{+}$ 

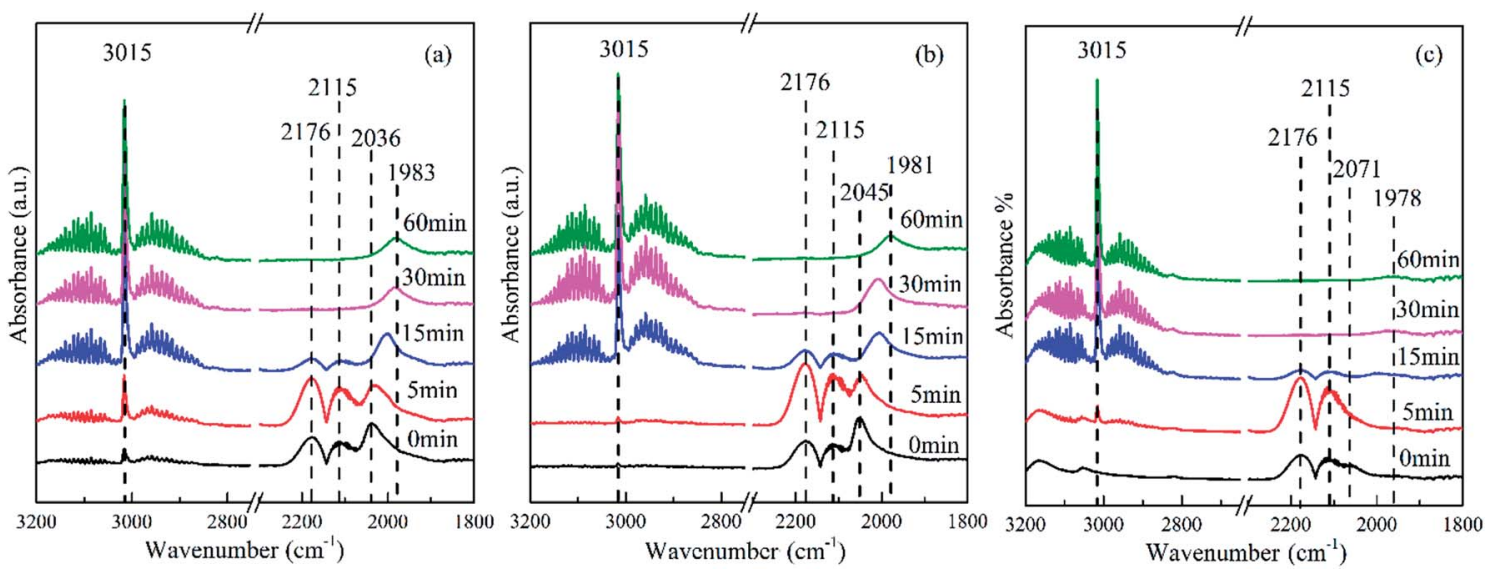

Fig. 7 In situ FTIR spectra of the hydrogenation reaction over the reduced catalysts with adsorbed $\mathrm{CO}$ at $205^{\circ} \mathrm{C}$ in a closed system: (a) $\mathrm{Co}-\mathrm{Si}$, (b) Co-0.1GSi, and (c) Co-1.0GSi. The spectra were obtained at 0, 5, 15, 30, and $60 \mathrm{~min}$.

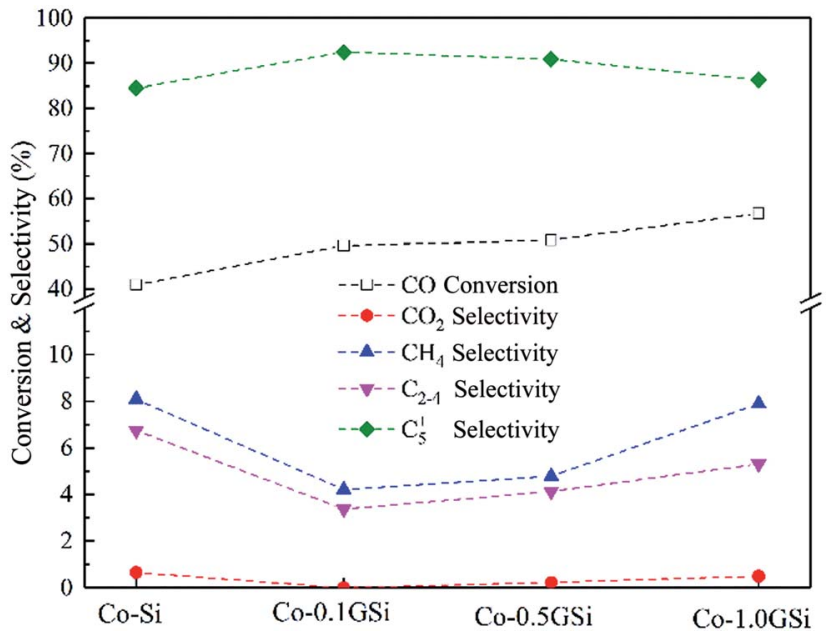

Fig. $8 \mathrm{CO}$ conversion and product selectivity over Co-xGSi at $205^{\circ} \mathrm{C}$, 2.0 $\mathrm{MPa}, \mathrm{H}_{2} / \mathrm{CO}=2$, and $2800 \mathrm{~cm}^{3}$ STP per g per h space velocity.

products, leading to higher $\mathrm{CO}$ conversion and $\mathrm{C}_{5}{ }^{+}$product selectivity. An increase in CO conversion from $41.0 \%$ to $56.7 \%$ was observed for the Co-1.0GSi catalyst as compared to that for the Co-Si catalyst. This was due to the smaller cobalt particle sizes and higher reducibility of the catalysts, as reported in Tables 1 and 2; more hcp cobalt exposed on the catalyst surface is shown in Fig. 2(e), and more adsorption amount of $\mathrm{H}_{2}$ and $\mathrm{CO}$ is shown in Table 2 .

With the addition of $0.1 \mathrm{wt} \%$ and $0.5 \mathrm{wt} \%$ graphene, the selectivity to $\mathrm{C}_{5}{ }^{+}$products was $92.4 \%$ and $90.9 \%$, respectively, probably due to the fact that the concentration and stability of adsorbed CO was increased under the reaction conditions, which was in agreement with the results of $\mathrm{CO}$ desorption presented in Fig. 6 and Table 2. While a decline in the selectivity to methane from $8.1 \%$ to $4.2 \%$ was seen for the Co-0.1GSi catalyst in comparison with that in the Co-Si catalyst, probably due to the stronger intensity of adsorbed CO and higher concentrations of carbon species. Fig. 8 also shows that the $\mathrm{CO}_{2}$ formation rate slightly decreased, but increased at higher graphene contents, which can be ascribed to the increased partial pressure of water due to the higher CO conversion in the FTS reaction. ${ }^{\mathbf{4 4}}$

The performance of the Co-0.1GSi catalyst at the temperatures of $205-235{ }^{\circ} \mathrm{C}$ was investigated, as shown in Fig. 9. With the increasing temperatures, the conversion of $\mathrm{CO}$ and the selectivity to $\mathrm{CH}_{4}$ and $\mathrm{CO}_{2}$ notably increased, and the selectivity to $\mathrm{C}_{5}{ }^{+}$products slightly decreased. The $\mathrm{CO}$ conversion of the Co-0.1GSi catalyst at $225{ }^{\circ} \mathrm{C}$ was $78.9 \%$ larger than that of $\mathrm{Co} /$

Table 3 Summary of the Co-graphene-silica catalyst performance and product distribution for the FTS reaction $\left(205^{\circ} \mathrm{C}, 2.0 \mathrm{MPa}, \mathrm{H}_{2} / \mathrm{CO}=2\right.$, and $2800 \mathrm{~cm}^{3}$ STP per g per $\mathrm{h}$ space velocity after $50 \mathrm{~h}$ on-stream)

\begin{tabular}{|c|c|c|c|c|c|c|c|c|c|c|c|}
\hline Sample $^{a}$ & $X_{\mathrm{CO}}(\%)$ & \multicolumn{4}{|c|}{ Product selectivity (\% C) } & $\mathrm{WTY}^{b}$ & $\alpha$ & \multicolumn{4}{|c|}{ Product distribution (wt\%) } \\
\hline Co-0.1GSi & 49.6 & 0.0 & 4.2 & 3.4 & 92.4 & 5.7 & 0.91 & 25.4 & 22.9 & 29.7 & 22.0 \\
\hline Co-0.5GSi & 50.8 & 0.2 & 4.8 & 4.1 & 90.9 & 6.3 & 0.92 & 23.6 & 21.7 & 31.5 & 23.2 \\
\hline Co-1.0GSi & 56.7 & 0.5 & 7.9 & 6.3 & 85.3 & 6.6 & 0.94 & 17.7 & 20.2 & 36.0 & 26.1 \\
\hline
\end{tabular}

${ }^{a}$ Catalyst weight was 1.00 g. ${ }^{b}$ Activity per unit weight catalyst (weight-time yield, WTY), ( $\mu$ mol CO per $g_{\text {cat }}$ per s). 


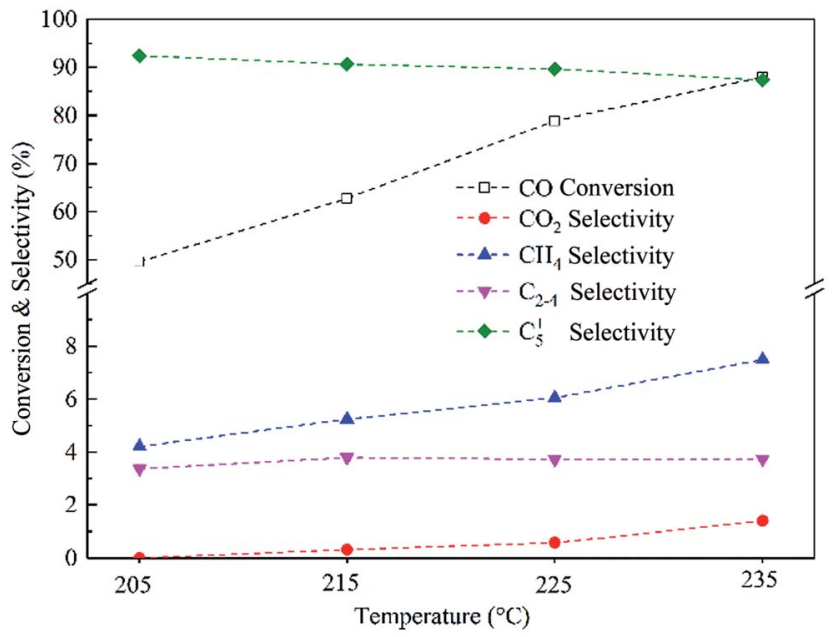

Fig. 9 The CO conversion and product selectivity over the Co-0.1GSi catalyst at different reaction temperatures, $2.0 \mathrm{MPa}, \mathrm{H}_{2} / \mathrm{CO}=2$, and $2800 \mathrm{~cm}^{3}$ STP per $\mathrm{g}$ per $\mathrm{h}$ space velocity.

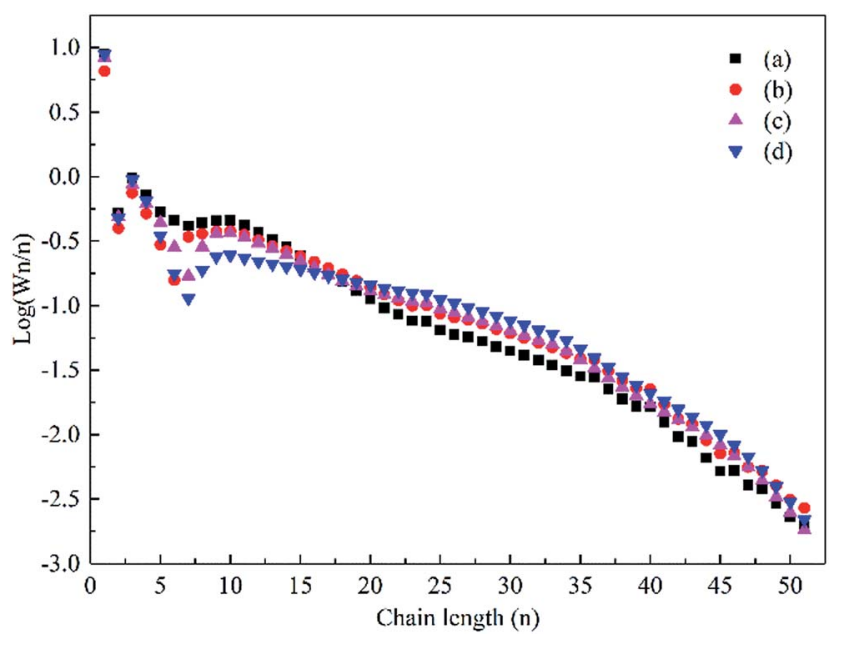

Fig. 10 The ASF distribution of the hydrocarbon products over the Co-xGSi catalysts: (a) Co-Si, (b) Co-0.1GSi, (c) Co-0.5GSi, and (d) Co-1.0GSi.

graphene and $\mathrm{Co} / 50 \mathrm{C}-\mathrm{SiO}_{2}$-air under similar reaction conditions, as listed in Table 3. Moreover, the selectivity to $\mathrm{CH}_{4}$ of the Co-0.1GSi catalyst was $6.0 \%$ lower than that of the graphenesupported cobalt catalyst. Compared to the Co/graphene catalyst, the Co-0.1GSi catalyst had a lower water gas-shift reaction. The samples with an addition of small amount of graphene possess high activity and high selectivity and avoid high cost and low mechanical strength of graphene. Therefore, this study provides a possible method for the industrial application of graphene in FTS.

The heightened FTS performance of cobalt-graphene-silica nanocomposites was attributed to their larger surface area, providing more active surface, higher reducing properties, and smaller cobalt particle sizes; this resulted in a larger density of active sites, more stable $\mathrm{CO}$ adsorbed on the catalyst surface, and higher concentrations of hydrogen species, promoting hydrogenation of CO.

The hydrocarbon chain growth probability factor $(\alpha)$ described by the Anderson-Schulz-Flory (ASF) distribution model was determined for the catalysts based on the weight fraction of hydrocarbon species, as shown in Fig. 10. The $\alpha$ value was estimated via the ASF plot from the $\mathrm{C}_{10-35}$ hydrocarbon range due to the fact that the corresponding correlation coefficients were comparatively high (greater than 0.99). However, the $\alpha$ value of the $\mathrm{C}_{36}{ }^{+}$hydrocarbon for each sample was almost the same. The $\alpha$ value increased from 0.89 for the Co-Si catalyst to 0.94 for the Co-0.1GSi catalyst, as shown in Table 3 .

The product distribution presents a variation for heavy hydrocarbons, as detailed in Table 3. Compared to that for the Co-Si catalyst, the fraction of $\mathrm{C}_{19-29}$ for the Co-1.0GSi catalyst significantly increased to $36.0 \%$, but the fraction of naphtha $\left(\mathrm{C}_{5-12}\right)$ was clearly reduced to $17.7 \%$. As for the Co- $x \mathrm{GSi}$ catalysts, higher amounts of adsorbed $\mathrm{CO}$ could reduce the $\mathrm{H}_{2} / \mathrm{CO}$ ratio on the catalyst surface, resulting in lower concentrations of adsorbed hydrogen species, which in turn led to the production of heavier hydrocarbons. ${ }^{45}$ Therefore, it was demonstrated that graphene not only influenced the selectivity, but also affected the distribution of products in FTS.

\section{Conclusions}

Herein, catalysts, cobalt-graphene-silica nanocomposites, were prepared by a sol-gel method and investigated for FTS. Surface areas and pore volumes slightly enhanced due to the textural properties of the catalysts with the addition of graphene. Moreover, smaller cobalt particle sizes were obtained. The introduction of graphene could weaken the interaction between cobalt oxide and the silica support and visibly facilitate the reduction of the $\mathrm{Co}-x \mathrm{GSi}$ catalyst from $\mathrm{Co}^{2+}$ to $\mathrm{Co}^{0}$. This reduction was due to the fact that graphene located at the interface between cobalt and silica decreased the probability of the formation of cobalt species that were difficult to reduce. The concentration of hydrogen species and adsorbed CO species was higher than those of the catalyst without graphene. Moreover, the amount and stability of adsorbed CO were significantly enhanced by $0.1-0.5 \mathrm{wt} \%$ graphene. In addition, graphene could distinctly increase the FTS reaction activity, $\mathrm{C}_{5}^{+}$product selectivity, and the fraction of heavier hydrocarbons $\left(\mathrm{C}_{19}{ }^{+}\right)$.

\section{Acknowledgements}

We gratefully acknowledge the financial support of the National High Technology Research and Development Plan of China (863 plan, 2011AA05A204) and the Fundamental Research Funds for the Central Universities (No. 222201717013).

\section{References}

1 Y. Wang, Y. Jiang, J. Huang, J. Liang, H. Wang, Z. Li, J. Wu, M. Li, Y. Zhao and J. Niu, Fuel, 2016, 174, 17.

2 J. Eilers, S. A. Posthuma and S. T. Sie, Catal. Lett., 1990, 7, 253. 
3 M. E. Dry, Catal. Today, 2002, 71, 227.

4 J. C. Park, J. I. Kwon, S. W. Kang, D. H. Chun, H.-T. Lee, H. Jung and J.-I. Yang, RSC Adv., 2017, 7, 8852.

5 J. Kang, X. Wang, X. Peng, Y. Yang, K. Cheng, Q. Zhang and Y. Wang, Ind. Eng. Chem. Res., 2016, 55, 13008.

6 X. Peng, K. Cheng, J. Kang, B. Gu, X. Yu, Q. Zhang and Y. Wang, Angew. Chem., Int. Ed., 2015, 54, 4553.

7 H. Zhang, H. Ma, H. Zhang, W. Ying and D. Fang, Catal. Lett., 2012, 142, 131.

8 J. Xie, H. M. Torres Galvis, A. C. Koeken, A. Kirilin, A. I. Dugulan, M. Ruitenbeek and K. P. de Jong, ACS Catal., 2016, 6, 4017.

9 K. Cheng, V. Subramanian, A. Carvalho, V. V. Ordomsky, Y. Wang and A. Y. Khodakov, J. Catal., 2016, 337, 260.

10 S. Chen, C. Wang, J. Li, Y. Zhang, J. Hong, X. Wen and C. Liu, Catal. Sci. Technol., 2015, 5, 4985.

11 A. Y. Khodakov, W. Chu and P. Fongarland, Chem. Rev., 2007, 107, 1692.

12 S. Krishnamoorthy, M. Tu, M. P. Ojeda, D. Pinna and E. Iglesia, J. Catal., 2002, 211, 422.

13 E. Marceau, M. Che, J. Čejka and A. Zukal, ChemCatChem, 2010, 2, 413.

14 T. M. Eggenhuisen, P. Munnik, H. Talsma, P. E. de Jongh and K. P. de Jong, J. Catal., 2013, 297, 306.

15 J. Du, J. Yan, J. Hong, Y. Zhang, S. Chen and J. Li, RSC Adv., 2015, 5, 60534.

16 J. Li, T. Wang, L. Wu and X. Li, RSC Adv., 2016, 6, 89770.

17 K. Cheng, L. Zhang, J. Kang, X. Peng, Q. Zhang and Y. Wang, Chem.-Eur. J., 2015, 21, 1928.

18 J. W. Bae, S. J. Park, M. H. Woo, J. Y. Cheon, K. S. Ha, K. W. Jun, D. H. Lee and H. M. Jung, ChemCatChem, 2011, 3, 1342 .

19 J. Zhang, J. Chen, J. Ren, Y. Li and Y. Sun, Fuel, 2003, 82, 581.

20 A. Y. Khodakov, Catal. Today, 2009, 144, 251.

21 J. Yang, E. Z. Tveten, D. Chen and A. Holmen, Langmuir, 2010, 26, 16558.

22 T. O. Eschemann, W. S. Lamme, R. L. Manchester, T. E. Parmentier, A. Cognigni, M. Rønning and K. P. de Jong, J. Catal., 2015, 328, 130.

23 W. Luo, W. H. Doh, Y. T. Law, F. Aweke, A. KsiazekSobieszek, A. Sobieszek, L. Salamacha, K. Skrzypiec, F. Le Normand, A. Machocki and S. Zafeiratos, J. Phys. Chem. Lett., 2014, 5, 1837.
24 S. L. Soled, E. Iglesia, R. A. Fiato, J. E. Baumgartner, H. Vroman and S. Miseo, Top. Catal., 2003, 26, 101.

25 B. F. Machado and P. Serp, Catal. Sci. Technol., 2011, 2, 54.

26 J. Guo, F. Li, Y. Sun, X. Zhang and L. Tang, Electrochim. Acta, 2015, 167, 32.

27 S. Stankovich, D. A. Dikin, G. H. B. Dommett, K. M. Kohlhaas, E. J. Zimney, E. A. Stach, R. D. Piner, S. T. Nguyen and R. S. Ruoff, Nature, 2006, 442, 282.

28 A. K. Geim and K. S. Novoselov, Nat. Mater., 2007, 6, 183.

29 S. Karimi, A. Tavasoli, Y. Mortazavi and A. Karimi, Appl. Catal., A, 2015, 499, 188.

30 N. M. Julkapli and S. Bagheri, Int. J. Hydrogen Energy, 2015, 40, 948.

31 S. O. Moussa, L. S. Panchakarla, M. Q. Ho and M. S. Elshall, ACS Catal., 2014, 4, 535.

32 A. n. Martínez, C. López, F. Márquez and I. Díaz, J. Catal., 2003, 220, 486.

33 M. Nurunnabi and S. Q. Turn, Fuel Process. Technol., 2015, 130, 155.

34 G. Jacobs, J. A. Chaney, P. M. Patterson, T. K. Das and B. H. Davis, Appl. Catal., A, 2004, 264, 203.

35 J. Gong and X. Bao, Chem. Soc. Rev., 2017, 46, 1770.

36 B. Jongsomjit, J. Panpranot and J. G. Goodwin Jr, J. Catal., 2003, 215, 66.

37 J. S. Girardon, A. Constant-Griboval, L. Gengembre, P. A. Chernavskii and A. Y. Khodakov, Catal. Today, 2005, 106, 161.

38 C. V. Schenck, J. G. Dillard and J. W. Murray, J. Colloid Interface Sci., 1983, 95, 398.

39 J. Girardon, E. Quinet, A. Gribovalconstant, P. Chernavskii, L. Gengembre and A. Khodakov, J. Catal., 2007, 248, 143.

40 G. Kadinov, C. Bonev, S. Todorova and A. Palazov, J. Chem. Soc., Faraday Trans., 1998, 94, 3027.

41 T. Li, H. Wang, Y. Yang, H. Xiang and Y. Li, Fuel Process. Technol., 2014, 118, 117.

42 F. M. Mendes, C. A. Perez, F. B. Noronha, C. D. Souza, D. V. Cesar, H. J. Freund and M. Schmal, J. Phys. Chem. B, 2006, 110, 9155.

43 C. Qiu, B. Wu, S. Meng and Y. Li, Acta Chim. Sin., 2015, 73, 690.

44 A. Tavasoli, R. M. M. Abbaslou, M. Trepanier and A. K. Dalai, Appl. Catal., A, 2008, 345, 134.

45 J. Yang, W. Ma, D. Chen, A. Holmen and B. H. Davis, Appl. Catal., A, 2014, 470, 250. 